See discussions, stats, and author profiles for this publication at: https://www.researchgate.net/publication/310317182

\title{
Genetic parameters for fatty acids in intramuscular fat from feedlot-finished Nelore carcasses
}

Article in Animal Production Science · January 2016

DOI: $10.1071 /$ AN16107

CITATIONS

19 authors, including:

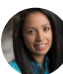

Carolyn Aboujaoude

University of Guelph

14 PUBLICATIONS 45 CITATIONS

SEE PROFILE

Fabieli Loise Braga Feitosa

University of Guelph

56 PUBLICATIONS 129 CITATIONS

SEE PROFILE
101

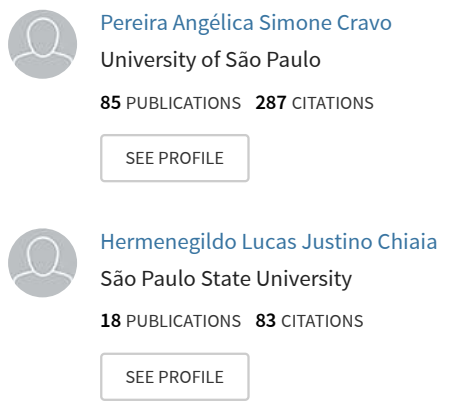

Some of the authors of this publication are also working on these related projects:

Taxa de infecção por Babesia bovis e B. bigemina em bovinos leiteiros e carrapatos View project

GENOME-WIDE SELECTION AND FEATURE SUBSET SELECTION OF MARKERS BY BAYESIAN NETWORKS IN BEEF CATTLE USING MULTIPLETRAIT MODEL VIEW PROJECT 


\title{
Genetic parameters for fatty acids in intramuscular fat from feedlot-finished Nelore carcasses
}

\author{
Carolyn Aboujaoude ${ }^{\mathrm{A}}$, Angélica Simone Cravo Pereira ${ }^{\mathrm{B}}$, Fabieli Louise Braga Feitosa ${ }^{\mathrm{A}}$, \\ Marcos Vinicius Antunes de Lemos ${ }^{\mathrm{A}}$, Hermenegildo Lucas Justino Chiaia ${ }^{\mathrm{A}}$, \\ Mariana Piatto Berton ${ }^{\mathrm{A}, \mathrm{E}}$, Elisa Peripolli ${ }^{\mathrm{A}}$, Rafael Medeiros de Oliveira Silva ${ }^{\mathrm{A}}$, \\ Adrielle Mathias Ferrinho ${ }^{\mathrm{B}}$, Lenise Freitas Mueller ${ }^{\mathrm{C}}$, Bianca Ferreira Olivieri ${ }^{\mathrm{A}}$, \\ Lucia Galvão de Albuquerque ${ }^{\mathrm{A}, \mathrm{D}}$, Henrique Nunes de Oliveira ${ }^{\mathrm{A}, \mathrm{D}}$, Humberto Tonhati ${ }^{\mathrm{A}, \mathrm{D}}$, \\ Rafael Espigolan ${ }^{\mathrm{A}}$, Rafael Tonussi ${ }^{\mathrm{A}}$, Daniel Mansan Gordo ${ }^{\mathrm{A}}$, Ana Fabricia Braga Magalhaes ${ }^{\mathrm{A}}$ \\ and Fernando Baldi ${ }^{\mathrm{A}, \mathrm{D}}$
}

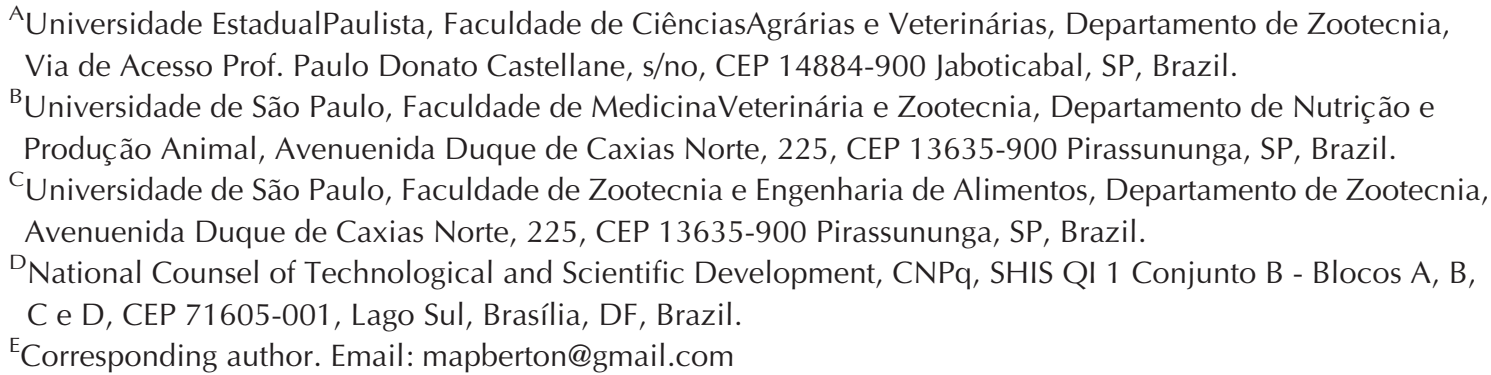

\begin{abstract}
The aim of the present study was to estimate covariance components and genetic parameters for beef fatty acid (FA) composition of intramuscular fat in the longissimus thoracis muscle in Nelore bulls finished in feedlot. Twenty-two FAs were selected. The heritability estimates for individual FAs ranged from 0.01 to 0.35 . The heritability estimates for myristic $(0.25 \pm 0.09)$, palmitic $(0.18 \pm 0.07)$, oleic $(0.28 \pm 0.09)$, linoleic $(0.16 \pm 0.06)$ and $\alpha$-linolenic $(0.35 \pm 0.10)$ FAs were moderate. Stearic, elaidic, palmitoleic, vaccenic, conjugated linoleic acid, docosahexanoic, eicosatrienoic and arachidonic FAs had heritability estimates below 0.15 . The genetic-correlation estimates between the individual saturated FAs (SFAs) were low and negative between myristic and stearic FAs $(-0.22 \pm 0.84)$, moderate between palmitic and myristic FAs $(0.58 \pm 0.56)$ and negative between palmitic and stearic FAs $(-0.69 \pm 0.45)$. The genetic correlations between the individual long-chain polyunsaturated FAs (PUFAs) were positive and moderate $(>0.30)$. However, the genetic-correlation estimates between long-chain PUFAs and $\alpha$-linolenic acid were low $(<0.30)$, except for the correlation between arachidonic and $\alpha$-linolenic acids. The genetic correlation estimates of the sums of SFAs with monounsaturated fatty acids and omega 6 FAs were low $(0.25 \pm 0.59$ and $-0.02 \pm 0.51$ respectively), high with PUFAs and omega 9 FAs $(-0.85 \pm 0.15$ and $0.86 \pm 0.17$ respectively) and moderate with omega $3 \mathrm{FAs}(-0.67 \pm 0.26)$. The present study demonstrated the existence of genetic variation and, hence, the possibility to increase the proportion of healthy and favourable beef FAs through selection. The results obtained in the study have provided knowledge to elucidate the additive genetic influence on FA composition of intramuscular fat. In addition, genetic-relationship estimates of intramuscular FA profile help seek strategies for genetic selection or genetic-based diet management to enhance the FA profile in Zebu cattle.
\end{abstract}

Additional keywords: genetic correlation, genetic variation, heritability, lipid composition, marbling, meat quality, Zebu cattle.

Received 20 February 2016, accepted 19 August 2016, published online 14 November 2016

\section{Introduction}

The two main strategies to change meat fatty acid (FA) composition are through genetic manipulation (selection and crossbreeding) and changes in production conditions, such as diet and management decisions (Wood and Enser 1997; Chung et al. 2007). The majority of studies aiming to estimate genetic parameters for meat FA profile have been conducted on Bos taurus breeds and their crosses, with heritability ranging from 0.00 to 0.78 (i.e. Malau-Aduli et al. 2000; Pitchford et al. 2002; Tait et al. 2007; Nogi et al. 2011; Ekine-Dzivenu et al. 
2014). Cesar et al. (2014) recently applied the genomic relationship matrix (GBLUP) model and estimated null to moderate heritabilities $(0.0-0.46)$ for meat FA profile in Nelore. According with De Smet et al. (2004) and Inoue et al. (2011), it is difficult to compare genetic parameter estimates for FA profile obtained in different studies because the genetic variation may be influenced by the differences in enzyme activities related to FA desaturation and by the differences in the degree of animal fattening.

The Zebu breeds are the predominant source of beef in tropical and subtropical regions. Therefore, the results obtained in the present study should indicate whether there is genetic variability for FA profile of intramuscular fat and whether selection is feasible to decrease harmful FA and increase health beneficial FA. Moreover, it is important to understand the genetic relationships within the intramuscular FA profile, so as to elucidate the physiological and metabolic bases that control their composition in Zebu cattle under tropical conditions. The aim of the present study was to estimate covariance components and genetic parameters of beef FA composition of intramuscular fat in the longissimus thoracis muscle in Nelore bulls finished in feedlot.

\section{Materials and methods}

\section{Animal and management}

In total, 963 Nelore bulls finished in a feedlot for a mean feeding days of 120 days (minimum 90 and maximum 150 days), and slaughtered at an average of 24 months of age, were used. The animals belonged to eight different farms located in the south-eastern, north-eastern and mid-western regions of Brazil, which participated in three beef-cattle breeding programs (Nelore Qualitas, Paint and DeltaGen). In these breeding programs, animals were selected on the basis of growth, finishing and sexual-precocity traits.

Breeding seasons were adopted at different periods on these farms. Therefore, calving seasons concentrated from August to October in some farms and from November to January in others, and weaning was performed at 7 months of age. The animals were raised under grazing conditions using Brachiaria sp. and Panicum sp. as forage, and were given free access to mineral salt. After 1 year of age, the breeding animals were selected and the rest remained in feedlot. During feedlotting, the forage : concentrate ratio ranged from $50: 50$ to $70: 30$, depending on the farm. In general, whole-plant corn or sorghum silage was used as a high-quality forage. Grains of corn and sorghum, and soybeans, soybean meal, or sunflower seeds were used as protein concentrate. The criterion used by farmers for slaughtering the animals was weight $(500-550 \mathrm{~kg})$. The descriptive statistics for hot carcass weight and backfat thickness level are shown in Table 1.

Slaughter was undertaken in commercial slaughterhouses (22 kill groups), in accordance with the Brazilian Federal Inspection Service procedures. After $48 \mathrm{~h}$, at $0-2^{\circ} \mathrm{C}$, the samples were removed from the longissimus thoracis muscle (at least $3.0 \mathrm{~kg}$, including muscle and bone), from between the 12th and 13th ribs from each animal. Samples were placed in airtight plastic bags and stored at $-80^{\circ} \mathrm{C}$. The percentage of intramuscular fat in the longissimus thoracis muscle was obtained by the method proposed by Bligh and Dyer et al. (1959).

\section{Genotyping of animals}

In total, 1616 animals were genotyped with a high-density single-nucleotide polymorphism (SNP) chip (Illumina HighDensity Bovine BeadChip, 777000; BovineHD BeadChip assay; 700k, Illumina Inc., San Diego, CA, USA). These animals were feedlot bulls, and some of them were half-sibs of animals with FA records. The SNP markers located on sex chromosomes, monomorphic, with unknown genomic position, and minor allele frequency of $<0.05$, call rate $<90 \%$, and markers with excess heterozygosity, as well as samples with a call rate $<90 \%$, were not considered in the analysis. After the SNP quality control, 470007 SNPs were available for 1556 samples.

\section{FA analysis}

Muscle samples were collected, freeze-dried and ground for FA analyses. The beef FAs were extracted from intramuscular fat of the longissimus thoracis muscle by using the method described in Folch et al. (1957). Lipids were extracted by homogenising the sample with a chloroform-methanol $(2: 1)$ solution. Sodium chloride $(\mathrm{NaCl})$ at $1.5 \%$ was added and the lipids were isolated. The fat extracted was methylated and the methyl esters were formed according to Kramer et al. (1997).

Fatty acid analysis in meat was performed at the Meat Science Laboratory (LCC) in the Department of Animal Nutrition and Production at FMVZ/USP, Pirassununga, Brazil. FAs were quantified by gas chromatography (GC-2010 Plus, Shimadzu AOC 20i auto-injector, Tokyo, Japan) using a SP-2560 capillary column $(100 \mathrm{~m} \times 0.25 \mathrm{~mm}$ in diameter with $0.02-\mathrm{mm}$ thickness, Supelco, Bellefonte, PA, USA). The initial temperature was $70^{\circ} \mathrm{C}$, and was then gradually increased $\left(13^{\circ} \mathrm{C} / \mathrm{min}\right)$ up to $175^{\circ} \mathrm{C}$, where it was held for $27 \mathrm{~min}$, until further increasing at a rate of $4^{\circ} \mathrm{C} / \mathrm{min}$ until it reached $215^{\circ} \mathrm{C}$, where it was held for $31 \mathrm{~min}$. Hydrogen $\left(\mathrm{H}_{2}\right)$ was used as the gas flow at $40 \mathrm{~cm}^{3} / \mathrm{s}$. FAs were identified by comparison of retention times of methyl esters of the samples with those of the FA standard C4-C24 (FAME mix, Sigma, Bellefonte, PA, USA), vaccenic acid: C18:1 t11 (V038-1G, Sigma), conjugated linoleic acid (CLA): C18:2 trans-10 cis-12 (UC-61M $100 \mathrm{mg}$ ), CLA: C18:2 cis-9 trans-11 (UC-60M $100 \mathrm{mg}$ ) and tricosanoic acid (Sigma). FAs were quantified by normalising the area under the curve of methyl esters by using the GS solution 2.42 software. FA concentrations were expressed as a percentage of total FA methyl esters (FAMEs) quantified. Twenty FAs (16 individual FAs and 6 groups of FAs) were selected (Table 1).

\section{Quantitative genetic analysis}

The contemporary groups (CGs) included animals born on the same farm and in the same year, and from the same management group at yearling. The CGs with fewer than three records were eliminated from the analysis. Records exceeding three standard deviations above or below the mean of each $\mathrm{CG}$ were excluded. After data editing, a total of 937 animals with records for beef FA profile remained in the dataset. The model used for the covariance and genetic-parameter estimation included the 
Table 1. Descriptive statistics for hot carcass weight (HCW), backfat thickness (BFT), intramuscular fat percentage (IMF), profile of the individual saturated (SFAs), monounsaturated (MUFAs), polyunsaturated (PUFAs) and conjugated linolenic (CLAs) fatty acids and for the total SFAs, MUFAs, PUFAs, omega 3 (n3), omega 6 (n6) and omega 9 (n9), expressed as a percentage of total fatty acid methyl esters, in longissimus thoracis muscle from Nelore cattle

The concentration of fatty acids are expressed as a percentage of total fatty acid methyl esters (FAMEs) quantified. Total SFAs, $\mathrm{C} 4: 0+\mathrm{C} 6: 0+\mathrm{C} 8: 0+\mathrm{C} 10: 0+\mathrm{C} 11: 0+\mathrm{C} 12: 0+\mathrm{C} 13: 0+\mathrm{C} 14: 0+\mathrm{C} 15: 0+\mathrm{C} 16: 0+\mathrm{C} 17: 0+\mathrm{C} 18: 0+\mathrm{C} 21: 0+\mathrm{C} 24: 0 ;$ total MUFAs, $\mathrm{C} 16: 1+\mathrm{C} 17: 1 \mathrm{c} 10+\mathrm{C} 18: 1 \mathrm{t} 11+\mathrm{C} 15: 1 \mathrm{c} 10+\mathrm{C} 20: 1 \mathrm{c} 11+\mathrm{C} 24: 1+\mathrm{C} 22: 1 \mathrm{n} 9+\mathrm{C} 18: 1 \mathrm{n} 9 \mathrm{c}+\mathrm{C} 14: 1+\mathrm{C} 18: 1 \mathrm{n} 9 \mathrm{t}$, total PUFAs, C18:2 $\mathrm{n} 6+\mathrm{C} 18: 3 \mathrm{n} 3+\mathrm{C} 18: 3 \mathrm{n} 6+\mathrm{C} 20: 3 \mathrm{n} 3$ cis-8,11,14 (ETE) $+\mathrm{C} 20: 3 \mathrm{n} 6$ cis-11,14,17 (DGLA) + C20:4 n6 + C20:5 n3 + C22:6 n3; $\mathrm{n} 3, \mathrm{C} 18: 3 \mathrm{n} 3+\mathrm{C} 20: 3 \mathrm{n} 3$ cis-11,14,17 + C22:6n3 + C20:5 n3; n6, C18:3 n6 + C20:3 n6 cis-8,11,14 + C18:2 n6 + C20:4n6; and n9, $\mathrm{C} 18: 1 \mathrm{n} 9 \mathrm{c}+\mathrm{C} 18: 1 \mathrm{n} 9 \mathrm{t}+\mathrm{C} 24: 1 \mathrm{n} 9+\mathrm{C} 22: 1 \mathrm{n} 9$. s.d., standard deviation

\begin{tabular}{|c|c|c|c|c|c|}
\hline Trait $^{\mathrm{A}}$ & Nomenclature & Mean & s.d. & Min. & Max. \\
\hline HCW (kg) & & 278.0 & 24.0 & 145.0 & 370.0 \\
\hline BFT (mm) & & 4.90 & 2.7 & 1.0 & 23.0 \\
\hline IMF (\%) & & 0.83 & 0.42 & 0.12 & 3.61 \\
\hline \multicolumn{6}{|c|}{$S F A$} \\
\hline Myristic & $\mathrm{C} 14: 0$ & 2.13 & 0.54 & 0.66 & 4.39 \\
\hline Palmitic & $\mathrm{C} 16: 0$ & 21.03 & 2.49 & 6.85 & 29.94 \\
\hline Stearic & C18:0 & 12.56 & 4.88 & 0.00 & 25.86 \\
\hline \multicolumn{6}{|c|}{ MUFA } \\
\hline Myristoleic & C14:1 & 0.31 & 0.22 & 0.00 & 2.08 \\
\hline Palmitoleic & C16:1 & 2.18 & 0.79 & 0.16 & 4.91 \\
\hline Elaidic & $\mathrm{C} 18: 1 \mathrm{n} 9 \mathrm{t}$ & 1.92 & 4.46 & 0.00 & 21.6 \\
\hline Oleic & $\mathrm{C} 18: 1 \mathrm{n} 9 \mathrm{c}$ & 30.6 & 4.98 & 15.81 & 44.9 \\
\hline Vaccenic & C18:1 t11 & 1.29 & 0.94 & 0.14 & 5.67 \\
\hline \multicolumn{6}{|c|}{ PUFA } \\
\hline Linoleic & $\mathrm{C} 18: 2 \mathrm{n} 6$ & 8.32 & 3.63 & 1.14 & 21.85 \\
\hline Linolenic & $\mathrm{C} 18: 3 \mathrm{n} 6$ & 0.59 & 0.26 & 0.00 & 2.25 \\
\hline Eicosatrienoic (ETE) & C20:3 n3 cis-8,11,14 & 0.49 & 0.19 & 0.00 & 1.81 \\
\hline Dihomo-gamma-linolenic (DGLA) & C20:3 n6 cis- $11,14,17$ & 2.00 & 0.77 & 0.00 & 4.75 \\
\hline$\alpha$-Linolenic & C18:3 n3 & 0.89 & 2.61 & 0.00 & 15.29 \\
\hline Docosahexaenoic & $\mathrm{C} 22: 6 \mathrm{n} 3$ & 0.95 & 0.39 & 0.00 & 2.50 \\
\hline Arachidonic & C20:4 & 1.11 & 3.14 & 0.01 & 26.03 \\
\hline \multicolumn{6}{|c|}{$C L A$} \\
\hline CLA & C18:2 c9 t11 & 0.22 & 0.13 & 0.00 & 0.66 \\
\hline \multicolumn{6}{|c|}{ Total } \\
\hline Total SFAs & & 40.66 & 6.12 & 2.56 & 52.36 \\
\hline Total MUFAs & & 37.55 & 8.05 & 3.75 & 64.93 \\
\hline Total PUFAs & & 13.42 & 5.57 & 2.07 & 37.62 \\
\hline n3 & & 3.81 & 1.55 & 0.24 & 11.36 \\
\hline n6 & & 9.35 & 4.44 & 0.74 & 33.87 \\
\hline n9 & & 18.68 & 14.24 & 0.14 & 45.79 \\
\hline
\end{tabular}

random genetic additive effects, the fixed effects of the CG, and the age of the animal at slaughter as a covariable (linear and quadratic effects).

The genetic correlations were estimated by two-trait analysis between the 16 individual FAs, and also between six groups of FAs (sums of saturated FAs (SFA), monounsaturated FAs (MUFAs), polyunsaturated FAs (PUFAs), omega 9, omega 6 and omega 3). The heritability and variance-component (residual and genetic additive variance) estimates for each FA were obtained by one-trait analysis. The covariances and genetic parameters were estimated using the restricted maximum likelihood method, by using the Remlf90 and Airemlf90 softwares (Misztal et al. 2002) and considering an animal model (single-step genomic BLUP, ssGBLUP). Initially, the Remlf90 (EM-algorithm) software was applied until the analysis converged, then the covariance estimates obtained by Remlf90 software were utilised as starting values for Airemlf90 (AIalgorithm) software. The ssGBLUP model is a modification of BLUP with the numerator relationship matrix $\mathbf{A}^{-1}$ replaced by $\mathbf{H}^{-\mathbf{1}}$ (Aguilar et al. 2010), as follows:

$$
\mathbf{H}^{-1}=\mathbf{A}^{-1}+\left[\begin{array}{cc}
0 & 0 \\
0 & \mathbf{G}^{-1}-\mathbf{A}_{22}^{-1}
\end{array}\right],
$$

where $\mathbf{A}_{\mathbf{2 2}}$ is a numerator-relationship matrix for genotyped animals and $\mathbf{G}$ is a genomic-relationship matrix. The singlestep GBLUP procedure allows to incorporate into the analysis all information available, including those from genotyped and ungenotyped animals. Thus, it is not necessary that the number of animals with phenotypic records, genotypes and pedigree are the same. The genomic matrix (G) was calculated following VanRaden et al. (2009), as follows: 


$$
\mathbf{G}=\mathbf{Z D Z}^{\mathbf{I}} q,
$$

where $\mathbf{Z}$ is a matrix of gene content adjusted for allele frequencies, $\mathbf{D}$ is a weight matrix for SNP (initially $\mathbf{D}=\mathbf{I}$ ) and $q$ is a weighting factor. According to Vitezica et al. (2011), the normalising factor can be derived by ensuring that the average diagonal in $\mathbf{G}$ is close to that of $\mathbf{A}_{\mathbf{2 2}}$.

For the traits, the model can be represented by the following matrix form:

$$
\boldsymbol{y}=\boldsymbol{X} \boldsymbol{\beta}+\mathbf{Z} a+\boldsymbol{e},
$$

where $\boldsymbol{y}$ is the vector of observations, $\boldsymbol{\beta}$ is the vector of fixed effects, $\boldsymbol{a}$ is vector of direct additive genetic effects, $\mathbf{X}$ is known incidence matrix, $\mathbf{Z}$ is incidence matrix of the random additive direct genetic effect (associates vector $\boldsymbol{\beta}$ with vector $\boldsymbol{y}$ ) and $\boldsymbol{e}$ is the vector of the residual effect. It was assumed that $\mathbf{E}[\boldsymbol{y}]=\mathbf{X} \boldsymbol{b}$; $\operatorname{Var}(\boldsymbol{a})=\mathbf{H} \otimes \mathbf{S a}$ and $\operatorname{Var}(\mathrm{e})=\mathbf{I} \otimes \mathbf{S e}$, where $\mathbf{S a}$ is the covariance matrix for the additive genetic effect, Se is covariance matrix for residual effect, $\mathbf{H}$ is relationship matrix, $\mathbf{I}$ is identity matrix and, $\otimes$ is Kronecker product.

The standard deviation of genetic parameters was calculated as an alternative to the standard error. The standard deviation was obtained by repeatedly sampling parameter estimates from their asymptotic multivariate normal distribution, following the idea presented by Meyer and Houle (2013). The Airemlf90 software (Misztal et al. 2002) has an option to estimate the standard deviation for functions of covariances (heritability and genetic correlations). The pedigree file contained the identifications of the animal, sire and dam, with a total of 2873 animals (after pruning) in the relationship matrix. The data file contained 937 animals, including 131 sires and 899 cows, with progeny presenting phenotypic data for FA profile.

\section{Results and discussion}

The percentage of lipids in the longissimus thoracis muscle (Table 1) was lower than those reported by Holloway et al. (1990), Huerta-Leidenz et al. (1996) and Newman et al. (2002) and Cesar et al. (2014) for Bos taurus, Bos indicus and their crossbreds, also finished in feedlot. It is important to highlight, that the animals used in the present experiment were not castrated (bulls) and received a diet with a moderate energy content, since the forage: concentrate ratio ranged from $50: 50$ to $70: 30$ in the farms, resulting in a low percentage of lipid in beef. The descriptive statistics for the profile of the most relevant individual SFAs, MUFAs, CLA cis 9 trans11 and PUFAs and for the sums of the SFAs, MUFAs and PUFAs, omega 3, omega 6 and omega 9 are presented in Table 1.

Our mean concentrations agreed with those reported by Prado et al. (2003), Kelly et al. (2013) and Cesar et al. (2014) who also observed palmitic, stearic and oleic FAs at the highest concentrations, although in different proportions (Table 1). These differences observed by the authors could be due to the different degrees of carcass adipose tissue (Prado et al. 2003; Wood and Enser, 1997), since lower fat deposition can result in a higher polyunsaturated acid and lower oleic acid deposition (Rule et al. 1997). The individual MUFAs and PUFAs with the highest concentrations were oleic (C18:1 n9), vaccenic (C18:1 t11) and linoleic (C18:2 n6) acids (Table 1). In a study using samples from longissimus muscle, Ekine-Dzivenu et al. (2014) reported higher and lower concentrations for oleic $(40.13 \%)$ and vaccenic $(0.54 \%)$ acids, respectively, than those obtained in the present study. Comparing with other studies, the concentration of linoleic FA obtained in the present study was also relatively high $(8.32 \%)$. The linolenic and dihomogamma linolenic acid (DGLA) FAs presented concentrations of $0.59 \%$ and $2.00 \%$ respectively. The DGLA concentration was higher than those found by Cesar et al. (2014) (0.44\%) and EkineDzivenu et al. (2014) (0.18\%) and lower than the $5.39 \%$ estimated by Prado et al. (2003).

In the present study, the beef FA profile was composed mainly of SFAs $(40.66 \%)$ and MUFAs $(37.55 \%)$, followed by the PUFAs (13.43\%). Prado et al. (2003), also working with Nelore animals, reported the same tendency for the proportion of saturated and unsaturated FAs, being $43.93 \%$ (SFAs), $42.33 \%$ (MUFAs) and 12.08\% (PUFAs). Pitchford et al. (2002), using taurine breeds, and Cesar et al. (2014), using Nelore breed, also found similar concentrations between SFAs and MUFAs, namely, $47 \%$ and $47.5 \%$, and $47.23 \%$ and $48.34 \%$, respectively. Prado et al. (2003), Kelly et al. (2013) and Cesar et al. (2014) estimated a lower proportion of PUFAs, namely $12.08 \%, 1.26 \%$ and $2.87 \%$, respectively, than that obtained in the present study $(13.03 \%)$.

The heritability estimates for the myristic, palmitic, oleic, linoleic and $\alpha$ - linolenic acids were moderate (Table 2). The heritability estimated for linoleic FA $(0.16)$ was close to that reported by Tait et al. (2007), 0.23 in a study using Angus cattle. However, Nogi et al. (2011) and Inoue et al. (2011) reported higher heritability estimates for linoleic FA in the intramuscular fat of muscle of Japanese black cattle, namely 0.34 and 0.58 respectively. Pitchford et al. (2002) estimated heritabilities for the myristic (0.18) and palmitic (0.21) FAs close to those obtained in the present study. Cesar et al. (2014) estimated low heritabilities for these FAs, ranging from 0.08 to 0.17 . However, Ekine-Dzivenu et al. (2014) reported a high estimate for the miristoleic FA (0.51) and Nogi et al. (2011) also reported high estimates for myristic $(0.70)$, palmitic $(0.65)$, myristoleic (0.60) and linoleic (0.58) FAs.

The moderate heritability estimate $(0.28)$ for oleic acid obtained in the present study suggests that selection is feasible to change the concentration of this FA in beef. Kim and Ntambi (1999) reported that the palmitoleic and oleic acids are produced from saturated FAs, such as palmitic and stearic acids, by the action of stearoyl-CoA desaturase enzyme. Despite the biological importance of $\alpha$-linolenic acid (Daley et al. 2010) and the moderate heritability obtained, the small additive variance of this FA showed that it could hardly be improved through selection. The stearic, elaidic, palmitoleic, vaccenic, docosahexanoic, eicosatrienoic and arachidonic FAs and CLA had low heritability estimates. Similar results were reported by Ekine-Dzivenu et al. (2014) and Pitchford et al. (2002) for stearic, Ekine-Dzivenu et al. (2014) and Kelly et al. (2013) for vaccenic, CLA-cis Cesar et al. (2014) and Ekine-Dzivenu et al. (2014) for vaccenic, and Cesar et al. (2014) for araquidonic FAs.

The heritability estimates for total SFAs, MUFAs, omega 3 and omega 9 were low, suggesting that the genetic additive component had only a small contribution to the phenotypic 
Table 2. Additive genetic, residual variance and heritability $\left(\mathrm{h}^{2}\right)$ estimates for the profile of the most relevant individual saturated (SFAs), monounsaturated (MUFAs), polyunsaturated (PUFAs) and conjugated linolenic (CLAs) fatty acids and for the sum of the SFAs, MUFAs, PUFAs, omega 3 (n3), omega 6 (n6) and omega 9 (n9), in longissimus thoracis muscle from Nelore cattle

The concentration of fatty acids are expressed as a percentage of total fatty acid methyl esters (FAMEs) quantified. Total SFAs, $\mathrm{C} 4: 0+\mathrm{C} 6: 0+\mathrm{C} 8: 0+\mathrm{C} 10: 0+\mathrm{C} 11: 0+\mathrm{C} 12: 0+\mathrm{C} 13: 0+\mathrm{C} 14: 0+\mathrm{C} 15: 0+\mathrm{C} 16: 0+\mathrm{C} 17: 0+\mathrm{C} 18: 0+\mathrm{C} 21: 0+\mathrm{C} 24: 0) ;$ total MUFAs, $\mathrm{C} 16: 1+\mathrm{C} 17: 1 \mathrm{c} 10+\mathrm{C} 18: 1 \mathrm{t} 11+\mathrm{C} 15: 1 \mathrm{c} 10+\mathrm{C} 20: 1 \mathrm{c} 11+\mathrm{C} 24: 1+\mathrm{C} 22: 1 \mathrm{n} 9+\mathrm{C} 18: 1 \mathrm{n} 9 \mathrm{c}+\mathrm{C} 14: 1+\mathrm{C} 18: 1 \mathrm{n} 9 \mathrm{t}) ;$ total of PUFAs $\mathrm{C} 18: 2 \mathrm{n} 6+\mathrm{C} 18: 3 \mathrm{n} 3+\mathrm{C} 18: 3 \mathrm{n} 6+\mathrm{C} 20: 3 \mathrm{n} 3$ cis-8,11,14 (ETE) $+\mathrm{C} 20: 3 \mathrm{n} 6$ cis-11,14,17 (DGLA) + C20:4 n6 + C20:5 n3 + C22:6 $\mathrm{n} 3 ; \mathrm{n} 3, \mathrm{C} 18: 3 \mathrm{n} 3+\mathrm{C} 20: 3 \mathrm{n} 3$ cis-1 1,14,17 + C22:6 n3 + C20:5 n3; n6, C18:3 n6 + C20:3 n6 cis-8, 11,14 + C18:2 n6 + C20:4 n6; and $\mathrm{n} 9, \mathrm{C} 18: 1 \mathrm{n} 9 \mathrm{c}+\mathrm{C} 18: 1 \mathrm{n} 9 \mathrm{t}+\mathrm{C} 24: 1 \mathrm{n} 9+\mathrm{C} 22: 1 \mathrm{n} 9$

\begin{tabular}{|c|c|c|c|c|}
\hline Fatty acid & Nomenclature & Additive genetic variance & Residual variance & $\mathrm{h}^{2}$ \\
\hline \multicolumn{5}{|c|}{ SFAs } \\
\hline Myristic & C14:0 & 0.06 & 0.18 & $0.25 \pm 0.09$ \\
\hline Palmitic & $\mathrm{C} 16: 0$ & 0.80 & 3.70 & $0.18 \pm 0.07$ \\
\hline Stearic & $\mathrm{C} 18: 0$ & 2.46 & 18.32 & $0.12 \pm 0.05$ \\
\hline \multicolumn{5}{|c|}{ MUFAs } \\
\hline Myristoleic & $\mathrm{C} 14: 1$ & 0.005 & 0.04 & $0.13 \pm 0.05$ \\
\hline Palmitoleic & $\mathrm{C} 16: 1$ & 0.000345 & 0.63 & $0.01 \pm 0.01$ \\
\hline Elaidic & $\mathrm{C} 18: 1 \mathrm{n} 9 \mathrm{t}$ & 1.22 & 15.98 & $0.07 \pm 0.03$ \\
\hline Oleic & $\mathrm{C} 18: 1 \mathrm{n} 9 \mathrm{c}$ & 4.06 & 10.51 & $0.28 \pm 0.09$ \\
\hline Vaccenic & $\mathrm{C} 18: 1 \mathrm{t} 11$ & 0.04 & 0.33 & $0.10 \pm 0.04$ \\
\hline \multicolumn{5}{|c|}{ PUFAs } \\
\hline Linoleic & $\mathrm{C} 18: 2 \mathrm{n} 6$ & 1.07 & 5.57 & $0.16 \pm 0.06$ \\
\hline Linolenic & $\mathrm{C} 18: 3 \mathrm{n} 6$ & 0.003 & 0.04 & $0.07 \pm 0.04$ \\
\hline$\alpha$-Linolenic & $\mathrm{C} 18: 3 \mathrm{n} 3$ & 0.002 & 0.003 & $0.35 \pm 0.10$ \\
\hline Docosahexaenoic & $\mathrm{C} 22: 6 \mathrm{n} 3$ & 0.016 & 0.11 & $0.13 \pm 0.06$ \\
\hline Arachidonic & $\mathrm{C} 20: 4 \mathrm{n} 6$ & 0.001 & 2.82 & $0.01 \pm 0.01$ \\
\hline $\begin{array}{l}\text { Eicosatrienoic Dihomo-gamma- } \\
\text { linolenic (DGLA) }\end{array}$ & C20:3 n6 cis- $11,14,17$ & 0.05 & 0.45 & $0.10 \pm 0.04$ \\
\hline Eicosatrienoic (ETE) & $\mathrm{C} 20: 3$ n3 cis- $8,11,14$ & 0.001 & 0.03 & $0.14 \pm 0.05$ \\
\hline \multicolumn{5}{|c|}{$C L A$} \\
\hline CLA & $\mathrm{C} 18: 2 \mathrm{c} 9 \mathrm{t} 11$ & 0.0003 & 0.01 & $0.02 \pm 0.01$ \\
\hline \multicolumn{5}{|c|}{ Total } \\
\hline Total SFAs & & 2.37 & 26.12 & $0.08 \pm 0.03$ \\
\hline Total MUFAs & & 3.55 & 43.45 & $0.08 \pm 0.04$ \\
\hline Total PUFAs & & 4.12 & 15.97 & $0.20 \pm 0.08$ \\
\hline $\mathrm{n} 3$ & & 0.11 & 1.86 & $0.06 \pm 0.03$ \\
\hline n6 & & 2.58 & 9.48 & $0.21 \pm 0.07$ \\
\hline n9 & & 8.89 & 125.3 & $0.07 \pm 0.03$ \\
\hline
\end{tabular}

variation of these FAs in zebu cattle. However, moderate heritabilities were obtained for total PUFAs and omega 6. Cesar et al. (2014) and Ekine-Dzivenu et al. (2014) also estimated a low heritability for SFAs and MUFAs and moderate values for omega 3 and omega 6. Similar to our results, low to moderate heritability estimates for PUFAs (0.05-0.12), MUFAs (0.06-0.20) and SFAs (0.07-0.30) were reported by Malau-Audli et al. (2000), Pitchford et al. (2002) and Ekine-Dzivenu et al. (2014). Nevertheless, other studies have presented higher heritability estimates for these groups of FAs than those in the present study, being 0.47 for PUFAs, 0.35-0.66 for SFAs and 0.35-0.68 for MUFAs in Japanese black cattle (Inoue et al. 2011; Nogi et al. 2011). Unlike in our study, Kelly et al. (2013), working with several breeds, also estimated a high heritability for SFAs (0.54) and MUFAs (0.54) and, therefore, concluded the existence of sufficient genetic variation for response to selection of FAs in subcutaneous fat of cattle. According to Ekine-Dzivenu et al. (2014), the wide range of heritability estimates for several FAs indicates different origins and mechanisms of synthesis, suggesting differences in the genetic mechanisms that rule the FAs in different tissues, cattle breeds or populations. The majority of studies that have estimated genetic parameters for beef FA composition have been conducted in taurine breeds, while the use of zebu breeds has been limited by the low number of records for these traits (Cesar et al. 2014).

The genetic-correlation estimates between the individual SFAs, MUFAs and PUFAs are presented in Table 3. The genetic correlations obtained in the present study should be treated with caution, particularly those that showed high standard deviations. It is important to highlight, that despite the high standard deviations obtained, previous researchers supported most of the direction of genetic-correlation estimates found in the present study.

The estimates of genetic correlation between myristic and stearic acids was low, whereas it was moderate between palmitic and myristic acids and between palmitic and stearic 


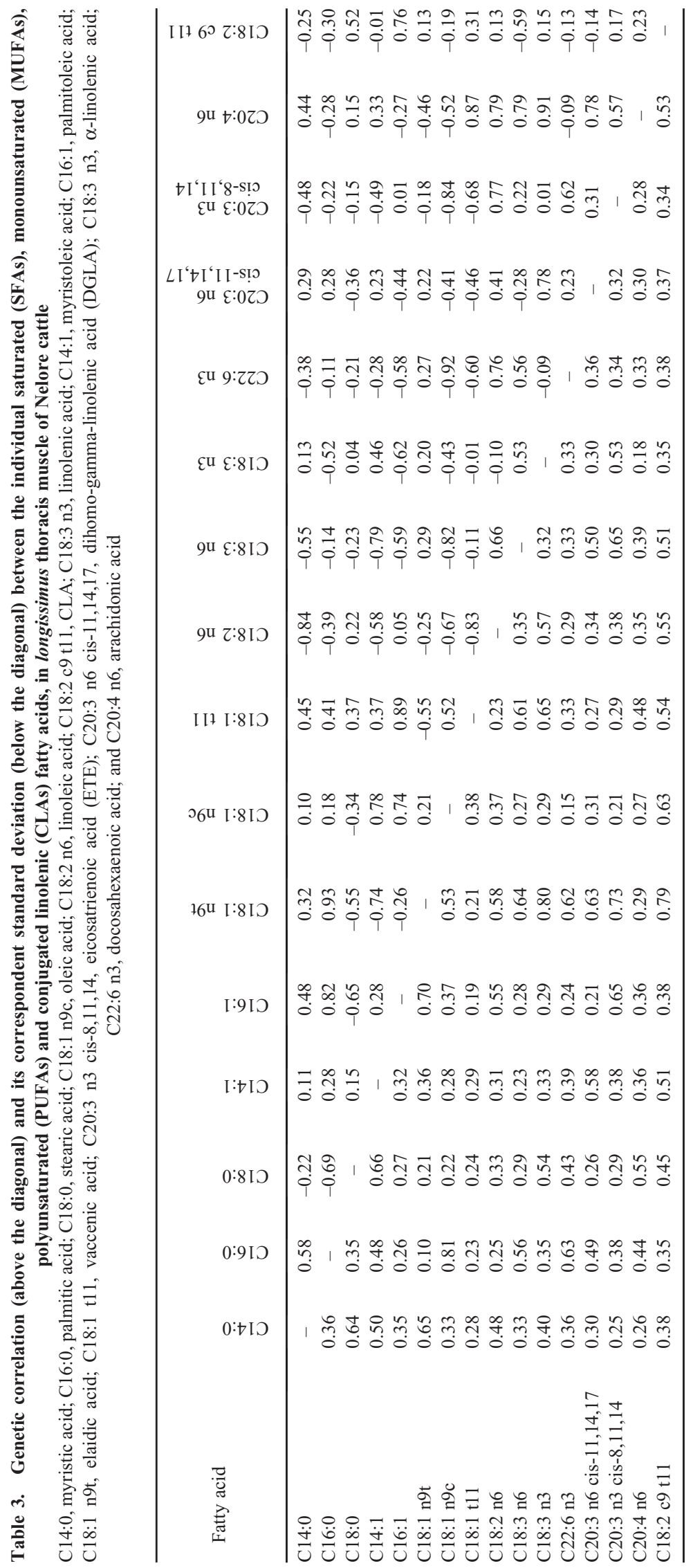


acids (Table 3). Ekine-Dzivenu et al. (2014) also estimated low genetic correlations (0.78) between these FAs, except between myristic and palmitic FAs. Like in the present study, these authors estimated a low genetic correlation $(-0.17)$ between the shorter-chain (myristic) and longer-chain (stearic) SFAs. Inoue et al. (2011) also reported high genetic-correlation estimates between the myristic and palmitic acids (0.70), but lower genetic correlations of these FAs with the longerchain SFAs (stearic, <0.28). Similar results were reported by Kelly et al. (2013), who observed a moderate and positive genetic correlation between myristic and palmitic FAs (0.55) and low genetic correlation between myristic and stearic FAs $(-0.09)$.

According to Drackley (2000) and Mapiye et al. (2012), the stearic FAs can be derived in fat deposits from shorter-chain SFAs through elongation. The negative and moderate geneticcorrelation estimate between stearic and palmitic acids pointed out that the host animal genes that regulate elongation may lead to a small reduction of stearic and palmitic acid in adipose tissue. The results of Ekine-Dzivenu et al. (2014) also supported this fact, since they reported moderate negative genetic correlations between stearic with palmitic FAs. The results obtained in the present study were in agreement with previous reports, where there was a genetic antagonism between medium-chain (C16:0) and longer-chain (C18:0) SFAs.

The genetic-correlation estimates between myristic and myristoleic FAs were positive and moderate, suggesting that the myristoleic FA is predominantly produced from its precursor, myristic acid, through desaturation (Ekine-Dzivenu et al. 2014). Additionally, the positive and high genetic correlation between palmitic and palmitoleic acids was obtained. The stearoyl-CoA desaturase is the rate-limiting enzyme required for the biosynthesis of MUFAs from SFAs. The stearoyl-CoA desaturase catalyses the desaturation of palmitoyl-CoA and stearoyl-CoA substrates at the $\Delta 9$ position, to produce de novo palmitoleoyl-CoA and oleoyl-CoA respectively (Estany et al. 2014). Thus, the results of the present study support the fact that palmitic and myristic acids are converted to palmitoleic and myristoleic acids respectively.

The genetic correlation estimate obtained between oleic acid and one of its precursors, stearic acid, suggests that host animal genes influencing stearic acid are likely to be associated with host genes that are involved in the production of oleic acid. Kelly et al. (2013), working with several cattle breeds used for beef production in Australia, also reported a moderate and negative genetic-correlation estimate $(-0.46)$ between oleic and stearic acids. Negative and high to moderate genetic-correlation estimate was obtained for linoleic acid with C14:0, and close to zero with palmitic and stearic acids (Table 3). Ekine-Dzivenu et al. (2014) also reported negative genetic correlations of linoleic acid with C14:0 (-0.35) and C16:0 (-0.88), but positive and moderate genetic correlations with $\mathrm{C} 18: 0(0.68)$. These results pointed out genetic antagonism between the genes that control the concentrations of myristic and the linoleic acid genes. The CLA (cis-9 trans-11) showed close to zero genetic correlations with $\mathrm{C} 16: 0, \mathrm{C} 14: 0$ and $\mathrm{C} 18: 0$. It is important to highlight, that most of the studies that have estimated genetic parameters for PUFAs in beef have reported few PUFAs (Inoue et al. 2011; Kelly et al. 2013; Ekine-Dzivenu et al. 2014).
Myristoleic acid showed negative and moderate geneticcorrelation estimates with elaidic acid $(-0.74 \pm 0.36)$, and positive and moderate with oleic acids, and near to zero with palmitoleic acid and vaccenic acids. Ekine-Dzivenu et al. (2014) found different results for the correlation between myristoleic and vaccenic acids $(-0.31)$, whereas Inoue et al. (2011) and Nogi et al. (2011) found negative correlations between myristoleic and oleic acids $(-0.43$ and -0.13 respectively). Although vaccenic acid showed positive and moderate genetic correlations with the oleic acid $(0.52 \pm$ 0.38 ), the high standard deviation value obtained did not allow confirmation of the genetic association between them. Nevertheless, it is important to highlight that a positive genetic correlation with a lower standard deviation between these FAs $(0.57 \pm 0.46)$ has been reported by Ekine-Dzivenu et al. (2014). Vaccenic acid, an isomer of oleic acid, is the principal ruminant trans fatty acid, and it is produced through the biohydrogenation of linoleic acid and $\alpha$-linolenic acid (Aldai et al. 2013).

The genetic-correlation estimates of individual MUFAs with individual PUFAs were mostly negative, suggesting a genetic antagonism between them (Table 3 ). The vaccenic acid FA is a common intermediate produced during ruminal biohydrogenation of linolenic acid and linoleic acid (Bessa et al. 2000). Therefore, the negative correlation between vaccenic acid FA with linolenic acid and linoleic acid suggests that host genes that influence vaccenic acid also influence genes involved in the production of the linoleic acid. Genetic-correlation estimates between CLA and most of the individual PUFAs were low and near zero; only the genetic-correlation estimate between CLA and arachidonic acid was moderate (Table 3).

A possible explanation for the moderate genetic correlation between linoleic and linolenic acids is the fact that linolenic acid is a precursor of linoleic acid (Hirayama et al. 2006). It is well known that CLA is produced from ruminal biohydrogenation of linoleic acid to stearic acid in the rumen by Butyrinvibrio fibrisolvens and other bacteria (Kepler et al. 1966; Jenkins 1993). Ekine-Dzivenu et al. (2014) estimated a high correlation between linoleic and stearic acids (0.68), but a low estimate of CLAs with stearic $(-0.39)$ and linoleic $(-0.25)$ acids. However, in the present study, close to zero genetic-correlation estimate was obtained between CLA and stearic and linoleic acids. The results of the present study showed that the genetic correlation among the individual long-chain PUFAs, such as arachidonic, eicosatrienoic and docosahexaenoic FAs, were positive and moderate. However, the genetic-correlation estimates between long-chain PUFAs and $\alpha$-linolenic acid were mostly low, except for the association between arachidonic and $\alpha$-linolenic acids.

The genetic-correlation estimates of the sums of SFAs with MUFAs and omega 6 were low and near zero, high with PUFAs and omega 9, and moderate with omega 3 (Table 4). EkineDzivenu et al. (2014) reported a negative and moderate genetic correlation between PUFAs and SFAs $(-0.41)$ and a positive and low genetic correlation between MUFAs and PUFAs $(0.20)$. However, the genetic correlation estimate between total PUFAs with total MUFAs was negative and high $(-0.84 \pm 0.19)$.

Only few studies have estimated genetic correlations among FAs in cattle meat, which limits the discussion and comparison of these results with others. The present study found that selection 
Table 4. Genetic (above the diagonal) and standard (below the diagonal) deviation of correlation estimates for the profile of sum of saturated (SFAs), monounsaturated (MUFAs), polyunsaturated (PUFAs), omega 3 (n3), omega 6 (n6) and omega 9 (n9) fatty acids, in longissimus thoracis muscle from Nelore cattle

Total SFA, C4:0 + C6:0 + C8:0 + C10:0 + C11:0 + C12:0 + C13:0 + C14:0 + $\mathrm{C} 15: 0+\mathrm{C} 16: 0+\mathrm{C} 17: 0+\mathrm{C} 18: 0+\mathrm{C} 21: 0+\mathrm{C} 24: 0 ;$ total MUFA, $\mathrm{C} 16: 1+\mathrm{C} 17: 1$ $\mathrm{c} 10+\mathrm{C} 18: 1 \mathrm{t} 11+\mathrm{C} 15: 1 \mathrm{c} 10+\mathrm{C} 20: 1 \mathrm{c} 11+\mathrm{C} 24: 1+\mathrm{C} 22: 1 \mathrm{n} 9+\mathrm{C} 18: 1 \mathrm{n} 9 \mathrm{c}+$ C14:1 + C18:1 n9t; total PUFA, C18:2 n6 + C18:3 n3 + C18:3 n6 + C20:3 n3 cis-8,11,14 (ETE) + C20:3 n6 cis-11,14,17 (DGLA) + C20:4 n6 + C20:5 n $3+$ C22:6n3; omega 3, C18:3 n3 + C20:3 n3 cis-11,14,17 + C22:6n 3 + C20:5n3; omega 6, C18:3 n6 + C20:3 n6 cis-8,11,14+C18:2n6+C20:4n6; and omega 9, $\mathrm{C} 18: 1 \mathrm{n} 9 \mathrm{c}+\mathrm{C} 18: 1 \mathrm{n} 9 \mathrm{t}+\mathrm{C} 24: 1 \mathrm{n} 9+\mathrm{C} 22: 1 \mathrm{n} 9$

\begin{tabular}{lccrrrr}
\hline Fatty acid & $\begin{array}{c}\text { Total } \\
\text { SFA }\end{array}$ & $\begin{array}{c}\text { Total } \\
\text { MUFA }\end{array}$ & $\begin{array}{r}\text { Total } \\
\text { PUFA }\end{array}$ & Omega 3 & Omega 6 & Omega 9 \\
\hline Total SFAs & & 0.25 & -0.85 & -0.67 & -0.02 & 0.86 \\
Total MUFAs & 0.59 & & -0.84 & -0.29 & -0.94 & 0.20 \\
Total PUFAs & 0.15 & 0.19 & & 0.76 & 0.76 & -0.75 \\
Omega 3 & 0.26 & 0.41 & 0.22 & & 0.75 & -0.54 \\
Omega 6 & 0.51 & 0.12 & 0.24 & 0.28 & & -0.80 \\
Omega 9 & 0.17 & 0.55 & 0.25 & 0.22 & 0.18 & \\
\hline
\end{tabular}

to increase concentrations of PUFAs and omega 6 should result in lowering the concentrations of total SFAs and MUFAs. The PUFAs and omega 6 showed moderate and higher heritability estimates than did SFAs and MUFAs, thus the PUFAs and omega 6 could be used as indicator traits to decrease the total SFAs. The genetic-correlation estimates among omega 3,6 and 9 suggest that the selection to increase omega 6 should also increase the concentration of omega 3 , and decrease the concentration of omega 9 in beef fat. Probably, this is due to the use of a common desaturase enzyme, which is a classic key to the metabolic pathways (Waitzberg and Borges 2002; Lopes and Juzwiak 2003; Hirayama et al. 2006).

The beef FA profile is a difficult and costly trait to measure since it depends on a progeny test. Therefore, it is very important to identify the indicator traits that are associated with the FA profile. In this sense, Feitosa et al. (2016) suggested that the percentage of intramuscular fat in the longissimus thoracis muscle could be used as the indicator trait of FA profile of zebu beef. Moreover, the identification of genomic regions that affect the beef FA composition may become an important and highly applicable tool to improve the nutritional value of zebu beef, given the expensive and difficult nature of collecting phenotypic records. Recently, Lemos et al. (2016), using the same dataset as in the present study, identified several genomic regions associated with quantitative trait loci, and harbouring genes such as ELOVL5, ESSRG, PCYT1A, ABC5, $A B C 6$ and $A B C 10$ related to lipid metabolism and FA composition. These regions can be used in future finemapping studies, whose primary function is to search for informative causative mutations and also for customised lowdensity chips that assist in a more cost-effective genetic evaluation for beef FA profile.

In Brazil, most of the slaughtered male animals are intact bulls, so as to take advantage in terms of higher growth rate when finishing them in feedlot. There have been few studies evaluating the effect of gender status on beef FA in zebu cattle.
The beef from intact Nelore bulls is characterised by lower carcass and beef fatness, and also lower concentrations of PUFAs and MUFAs, a lower PUFA: SFA ratio and higher concentrations of SFAs (Ruiz et al. 2005). The present study used a large database of animals belonging to different beef cattle-breeding programs, and animals that are commercialised in various regions of the country. Therefore, the information obtained should contribute to the selection and breeding programs improving beef quality of zebu cattle raised in tropical conditions.

Decreasing SFA intake and increasing unsaturated-fat intake is recommended and has several beneficial impacts on human health (Adams et al. 2010). However, some studies have reported that individual SFAs such as the stearic FA have neutral effects on cholesterol concentrations ( $\mathrm{Yu}$ et al. 1995). Moreover, the concentration of oleic FA, which is beneficial for flavour, human nutrition and fat softness (Kelly et al. 2013), could be increased, along with stearic acid. The moderate genetic correlation obtained between palmitic and palmitoleic acids, and between myristic and myristoleic acids, suggests that genetic differences in the activity of stearoyl-CoA desaturase gene may have existed among animals used in the present study. There is evidence of genetic differences in elongation activities (Kelly et al. 2013), and, in the present study, myristic acid showed a positive correlation with palmitic acid, but a low correlation with the stearic acid, which indicated that some animals exhibited a tendency to elongate specific, but not all, FAs.

The results obtained in the present study have provided knowledge to elucidate the additive genetic influence on fatty acid composition of intramuscular fat. In addition, geneticrelationship estimates among intramuscular FAs help seek strategies for genetic selection and/or genetic-based diet management to enhance the beef FA profile in zebu cattle.

\section{Acknowledgements}

This work was supported by the grants from São Paulo Research Foundation - FAPESP (\#2009/16118-5 and \#2011/21241-0), National Counsel of Technological and Scientific Development (CNPq) and CAPES (Coordination for the Improvement of Higher Education Personnel).

\section{References}

Adams TH, Walzem RL, Smith DR, Tseng S, Smith SB (2010) Hamburger high in total, saturated and trans-fatty acids decreases HDL cholesterol and LDL particle diameter, and increases TAG, in mildly hypercholesterolaemic men. British Journal of Nutrition 103, 91-98. doi:10.1017/S0007114509991516

Aguilar I, Misztal I, Johnson DL, Legarra A, Tsuruta S, Lawlor TJ (2010) A unified approach to utilize phenotypic, full pedigree, and genomic information for genetic evaluation of Holstein final score. Journal of Dairy Science 93, 743-752. doi:10.3168/jds.2009-2730

Aldai N, Renobales M, Barron LJR, Kramer JKG (2013) What are the trans fatty acids issues in foods after discontinuation of industrially produced trans fats? Ruminant products, vegetable oils, and synthetic supplements. European Journal of Lipid Science and Technology 115, 1378-1401. doi:10.1002/ejlt.201300072

Bessa RJB, Santos-Silva J, Ribeiro JMR, Portugal AV (2000) Reticulorumen biohydrogenation and the enrichment of ruminant edible products with linoleic acid conjugated isomers. Livestock Production Science 63, 201-211. doi:10.1016/S0301-6226(99)00117-7 
Bligh EG, Dyer WJ (1959) A rapid method of total lipid extraction and purification. Canadian Journal of Biochemistry and Physiology 37, 911-917. doi:10.1139/059-099

Cesar ASM, Regitano LCA, Mourao GB, Tullio RR, Lanna DPD, Nassu RT, Mudado MA, Oliveira PSN, Nascimento ML, Chaves AS, Alencar MM, Sonstergard TS, Garrik DJ, Reecy JM, Coutinho LL (2014) Genomewide association study for intramuscular fat deposition and composition in Nelore cattle. BMC Genetics 15, 39. doi:10.1186/1471-2156-15-39

Chung KY, Lunt DK, Kawachi H, Yano H, Smith SB (2007) Lipogenesis and stearoyl-CoA desaturase gene expression and enzyme activity in adipose tissue of short- and long-fed Angus and Wagyu steers fed corn- or haybased diets. Journal of Animal Science 85, 380-387. doi:10.2527/ jas.2006-087

Daley CA, Abbott A, Doyle PS, Nader GS, Larson S (2010) A review of fatty acid profiles and antioxidant content in grass-fed and grain-fed beef. Nutrition Journal 9, 10. doi:10.1186/1475-2891-9-10

De Smet S, Raes K, Demeyer D (2004) Meat fatty acid composition as affected by fatness and genetic factors: a review. Animal Research 53, 81-98. doi:10.1051/animres:2004003

Drackley JK (2000) Lipid metabolism. In 'Farm animal metabolism and nutrition'. (Ed. JPF D’Mello) pp. 97-119. (CAB International: Wallingford, UK)

Ekine-Dzivenu C, Chen L, Vinsky M, Aldai N, Dugan MER, Mcallister TA, Wang Z, Okine E, Li C (2014) Estimates of genetic parameters for fatty acids in brisket adipose tissue of Canadian commercial crossbred beef steers. Meat Science 96, 1517-1526. doi:10.1016/j.meatsci.2013. 10.011

Estany J, Ros-Freixedes R, Tor M, Pena R (2014) A functional variant in the stearoyl-CoA desaturase gene promoter enhances fatty acid desaturation in pork. PLoS One 9(1), e86177. doi:10.1371/journal.pone.0086177

Feitosa FLB, Olivieri BF, Aboujaoude C, Pereira ASC, Lemos MVA, Chiaia HLM, Berton MP, Peripolli E, Ferrinho AM, Mueller LF, Mazalli MR, Albuquerque LG, Oliveira HN, Tonhati H, Espigolan R, Tonussi RL, Silva RMO, Gordo DGM, Magalhães AFB, Aguilar I, Baldi F (2016) Genetic correlation estimates between beef fatty acid profile with meat and carcass traits in Nelore cattle finished in feedlot. Journal of Applied and Genetics doi:10.1007/s13353-016-0360-7

Folch J, Lees M, Sloane-Stanley GH (1957) A simple method for the isolation and purification of total lipids from animal tissues. The Journal of Biological Chemistry 226, 497-509.

Hirayama KB, Sperdião PGL, Neto UF (2006) Ácidos graxos polinsaturados de Cadeia Longa. The Electronic Journal Pediatric Gastroenterology Nutrition Liver Diseases 10, 3.

Holloway JW, Savell JW, Hamby PL, Baker JF, Stouffer JR (1990) Relationships of empty-body composition and fat distribution to live animal and carcass measurements in Bos indicus-Bos taurus crossbred cows. Journal of Animal Science 68, 1818-1826. doi:10.2527/1990. $6871818 \mathrm{x}$

Huerta-Leidenz NO, Cross HR, Savell JW, Lunt DK, Baker LS, Smith SB (1996) Fatty acid composition of subcutaneous adipose tissue from male calves at different stages of growth. Journal of Animal Science 74, 1256-1264. doi: 10.2527/1996.7461256x

Inoue K, Kobayashi M, Shoji N, Kato K (2011) Genetic parameters for fatty acid composition and feed efficiency traits in Japanese black cattle. Animal 5, 987-994. doi:10.1017/S1751731111000012

Jenkins TC (1993) Lipid metabolism in the rumen. Journal of Dairy Science 76, 3851-3863. [review]. doi:10.3168/jds.S0022-0302(93) 77727-9

Kelly MJ, Tume RK, Newman S, Thompson JM (2013) Genetic variation in fatty acid composition of subcutaneous fat in cattle. Animal Production Science 53, 129-133. doi:10.1071/AN12154

Kepler CR, Hirons KP, Mcneill JJ, Tove SB (1966) Intermediates and products of the biohydrogenation of linoleic acid by butyrin vibrio fibrisolvens. The Journal of Biological Chemistry 241, 1350-1354.
Kim YC, Ntambi JM (1999) Regulation of stearoyl-CoA desaturase genes: role in cellular metabolism and preadipocyte differentiation. Biochemical and Biophysical Research Communications 266, 1-4. doi:10.1006/bbrc. 1999.1704

Kramer JKG, Fellner V, Dugan MER (1997) Evaluating acid and base catalysts in the methylation of milk and rumen fatty acids with special emphasis on conjugated dienes and total trans fatty acids. Lipids 32, 1219-1228. doi:10.1007/s11745-997-0156-3

Lemos MV, Chiaia HLJ, Berton MP, Feitosa FLB, Aboujaoude C, Pereira ASC, Albuquerque LG, Ferrinho AM, Mueller LF, Mazalli MR, Furlan JJ, Carvalheiro R, Gordo DM, Tonussi R, Espigolan R, Silva RM, de Oliveira HN, Aguilar I, Baldi F (2016) Genome-wide association between single nucleotide polymorphisms with beef fatty acid profile in Nelore cattle using the single step procedure. BMC Genomics 17, 213.

Lopes A , Juzwiak F (2003) O uso de formulas infantil após o desmame. Temas de Pediatria. Nestle 74, 7-8.

Malau-Aduli AEO, Edriss MA, Siebert BD, Bottema CDK, Deland MPB, Pitchford WS (2000) Estimates of genetic parameters for triacylglycerol fatty acids in beef cattle at weaning and slaughter. Journal of Animal Physiology and Animal Nutrition 83, 169-180. doi:10.1046/j.1439-0396. 2000.00256.x

Mapiye C, Aldai N, Turner TD, Aalhus JL, Rolland DC, Kramer JKG, Dugan MER (2012) The labile lipid fraction of meat: from perceived disease and waste to health and opportunity. Meat Science 92, 210-220. doi:10.1016/j.meatsci.2012.03.016

Meyer K, Houle D (2013) Sampling based approximation of confidence intervals for functions of genetic covariance matrices. Proceedings Association for Advancement of Animal Breeding and Genetics 20, 523-526.

Misztal I, Tsuruta S, Strabel T, Auvray B, Druet T, Lee DH (2002) BLUPF90 and related programs (BGF90). In 'Proceedings of the 7th world congress on genetics applied to livestock production, 19-23 August 2002, Montpellier, (France)'. Communication no. 28-07.

Newman RE, Bryden WL, Fleck E, Ashes JR, Storlien LH, Downing JA (2002) Dietary n-3 and n-6 fatty acids alter avian metabolism: molecularspecies composition of breast-muscle phospholipids. British Journal of Nutrition 88, 19-28. doi:10.1079/BJN2002581

Nogi T, Honda T, Mukai F, Okagaki T, Oyama K (2011) Heritabilities and genetic correlations of fatty acid compositions in Longissimus muscle lipid with carcass traits in Japanese black cattle. Journal of Animal Science 89, 615-621. doi:10.2527/jas.2009-2300

Pitchford WS, Deland MPB, Siebert BD, Malau-Aduli AEO, Bottema CDK (2002) Genetic variation in fatness and fatty acid composition of crossbred cattle. Journal of Animal Science 80, 2825-2832. doi:10.2527/ 2002.80112825x

Prado IN, Moreira FB, Matsushita M, Souza NE (2003) Longissimus dorsi fatty acids composition of Bos indicus and Bos indicus $\times$ Bos taurus crossbred steers finished in pasture. Brazilian Archives of Biology and Technology 46, 599-606. doi:10.1590/S1516-89132003000400015

Ruiz MR, Matsushita M, Visentainer JV, Hernandez JA, Ribeiro ELA, Shimokomaki M, Reeves JJ, Souza NE (2005) Proximate chemical composition and fatty acid profiles of longissimus thoracis from pasture fed LHRH immunocastrated, castrated and intact Bos indicus bulls. South African Journal of Animal Science 35, 13-18.

Rule DC, Macneil MD, Short RE (1997) Influence of sire growth potential, time on feed, and growing-finishing strategy on cholesterol and fatty acids of the ground carcass and longissimus muscle of beef steers. Journal of Animal Science 75, 1525-1533. doi:10.2527/1997.7561525x

Tait R, Zhang S, Knight T, Bormann JM, Beitz D, Reecy J (2007) Heritability estimates for fatty acid quantity in Angus beef. Journal of Animal Science $\mathbf{8 5}, 58$.

VanRaden PM, Van Tassell CP, Wiggans GR, Sonstegard TS, Schnabel RD, Taylor JF, Schenkel FS (2009) Invited review: reliability of genomic 
predictions for North American Holstein bulls. Journal of Dairy Science 92, 16-24. doi:10.3168/jds.2008-1514

Vitezica ZG, Aguilar I, Misztal I, Legarra A (2011) Bias in genomic predictions for populations under selection. Genetical Research 93, 357-366. doi:10.1017/S001667231100022X

Waitzberg DL, Borges VC (2002) Gorduras. In 'Nutrição oral, enteral e parenteral na pratica clínica'. (Ed. DL Waitzberg) pp. 59-64. (Atheneu: São Paulo, Brazil)
Wood JD, Enser M (1997) Factors influencing fatty acids in meat and the role of antioxidants in improving meat quality. British Journal of Nutrition 78(Suppl. 1), S49-60. doi:10.1079/BJN19970134

Yu S, Derr J, Etherton TD, Krisetherton PM (1995) Plasma cholesterolpredictive equations demonstrate that stearic acid is neutral and monounsaturated fatty acids are hypocholesterolemic. The American Journal of Clinical Nutrition 61, 1129-1139. 